\title{
Augmented Reality in Education, AR Globe Project Assessment in Actual Teaching-Learning Environment
}

\author{
Hovhannes Mayilyan \\ YoungZone Culture (Shanghai) Co. Ltd, \\ Shanghai, P.R.China
}

\begin{abstract}
Over the years, technology has revolutionized our world and the utilization of advanced technologies in any industry has recorded better results. The usability of cutting-edge technologies in the teachinglearning process is redefining the role of educators and reshaping learning experiences. Augmented Reality (AR), a technology that augments the real world with realistic virtual information, in various form of multimedia content, provides new possibilities for the educational domain. The information delivery with Augmented Reality (AR) engages most of the sensory channels that intensifies the effectiveness of teaching-learning process and creates a more appealing learning environment. This paper, with the discussion of the AR Globe project, aims to provide an introduction to the Augmented Reality (AR) technology's implementation into real-life environment, to assess the potential of the technology in educational settings by outlining the attitude of learners towards the use of immersive multimedia content in their learning mediums.
\end{abstract}

Keywords: Augmented Reality; AR in Education, Learning Styles.

\section{Introduction}

The use of innovative technologies continually simplifies the way human lives. By creating new devices and systems technology aims to improve human productivity and extend life expectancy (Global Agenda Council on Ageing, 2016; Sandhu, 2016; Lichtenberg, 2015; Johnson, 1991). We apply technology in every aspect of our life; we utilize technology to communicate one another, to increase the efficiency and productiveness of our work, to create better and useful products, safer and faster transportation systems, discover new planets and universe, etc. Technology is the level of the social and economic development of the state, and society can be defined as advanced society if they have successfully applied technology (Thomas, 02018). 
On the other hand, it is commonly presumed that formal schooling is one of several important contributors to the economic growth of the nation.

It is well established that the systematic development and elevation of formal education in the region directly contributes the life quality, longevity, prosperity, and economic sustainability of the society.To this day, in most countries, states remain the primary entities holding the education system and defining the strategic direction and modernization for the public education of the society.

Therefore it's vital for each state to develop a formal education system that integrates new educational approaches and technologies into existing educational programs meanwhile promoting creative proposals to build a globally competitive society for the 21st century.

\section{Educational Technologies}

As any other industry education and learning process require advanced technological intervention for better productivity and final results. The results of the current implementation of technology in education indicate a positive impact on teaching/ learning process. It is obvious, lessons that are supported by technology will lead to more innovative forms of teaching and bring the learning capabilities to a new level.

To have a clear understanding of what is Educational Technology, it is important to define what is Technology and what is Education.

Because of its dynamic nature and wide-range of implementation, it is difficult to define and to understand the meaning of technology. This makes it not easy task for experts and individuals to bring a sole definition for the term technology(Hughes, 2005; Rhodes, 2001). An American historian of technology Thomas Hughes describes technology as a complex process, as complex as grasping the essence of politics (Hughes,2005).

Interestingly, in his another A century of invention and technological enthusiasm 1870-1970 book, Thomas Hughes describes Technology a unique tool that can help the wold to arrange solutions to problems that eventually will create new services to produce most needed products to develop better living conditions (Hughes, 2004). Another fundamental definition to technology was proposed by (Rhodes, 2001) as technology the successful utilization of achievement of science and engineering into different aspects of industries to create human satisfactory products. This definition was developed and expended by Burgelman. Based on (Burgelman, Christensen, \& Wheelwright, 2009) technology is the theoretical and practical knowledge of different science possessed by modern society that implemented in various fields of industry to develop new products and their production methods; services, and their delivery strategies.

Based on the Oxford Dictionary, the formal definition of education is given as "The process of receiving or giving systematic instruction, especially at a school or university" (Eeducation Oxford Dictionary). A more detailed definition describes education as a: 


\begin{abstract}
"conscious and well-planned effort in creating a learning environment and learning process so that learners will be able to develop their full potential for acquiring spiritual and religious strengths, develop self-control, personality, intelligence, morals and noble character and skills that one needs for him/herself, for the community, for the nation, and for the State (Indonesia. (n.d.)."
\end{abstract}

Being a continuous process education is a renewal of the meaning of experience that passes achievements and failures of the previous generations to the new generations that can create advanced values to help the development and progress of humankind linking the past, present and leading to the future. Learning is a unique power that we use to acquire knowledge and understanding of the world we live in and societies with an advanced level of education can transform the world into a better one (Dewey, 2015).

Educational Technology (EdTech) term is the evolution of different technological resource integration in teaching-learning process to deal with learning process with better outcomes (Hsu, Hung, \& Ching, 2013).

Educational Technology is a specially designed process of utilizing advanced technologies into existing educational systems to increase and improve the level and the quality of education. It helps to enhance the information delivery methods, creates a new interactive learning/ learning environment that helps to increase the productivity and efficiency of the educational system. Teachinglearning is a complex process, and systematic integration of new teaching approaches and techniques are necessary to achieve objectives (AECT Definitions of the Field 2008; Apter, 1967).

There are two equally essential approaches for educational technology implementation in modern education: hardware and software approach.

- Hardware approach: consisting of hardware device utilization in learning institutions such as gadgets, computers, laptops, and mobile phones.

- Software approach: development of software-based knowledge delivery materials to assist in teaching/ learning process. Derived from theoretically learned knowledge to develop a personal experience this strategy aims to support effective instruction and goal-oriented learning.

An excellent example of an idea of hardware and software implementation in education stands behind BYOD. BYOD stands for "Bring Your Own Device." BYOD is an ambitious proposal that expects learners to bring personal hardware devices to their learning environments. For this initiative, the "hardware device" means a personally owned portable, hand-held electronic device equipment with a processing unit that includes laptops, netbooks, tablets etc. The use of BYOD in the classroom will be used under the supervision of a teacher for educational and academic purposes, including but not limited to accessing digital libraries, educational applications, and learning-oriented games to enhance the students' learning ability (Grant, \& Barbour, 2013). An advantage of applying BYOD in education is that students can use technology that they are 
already familiar with and they have access at home to complete homeworks (Ally, \& Tsinakos 2014).

\section{Sensory-based Learning Styles}

Edgar Dale, an American educator, by researching the audio/video tools in teaching-learning process in 1960's developed the Cone of Experience a visual model of theories related to instructional design and learning process (Dale, 1969).

By examining the Dale's Cone of Experience, it can be observed, that Dale has used all the primary biological factors that have effects on individual's knowledge acquisition process (Fatt 2000). According to (Auer,2008) the five senses approach endeavors to awaken long dormant sensory experiences of nature and use those experiences to learn and is a useful biological advantage that helps reinforcing conventional learning.

People heavily relay on their five senses namely sight, touch, hearing, olfactory, and gustatory to collect information and experience the world (Bandler, \& Grinder, 1980). Each of the above-mentioned sense has it's unique location in the brain, a physical location where the collected experience is sent, processed, and stored. Accumulated information through five senses directed into three separate routes, to make analyze and convert it into a sort of knowledge. Our assimilation of this input can alter the collected data into something new, different from the original. Information recalled letter is the representation of what our sensory organs transmitted to us. Each model can be referred as a "representational system" (Hager, 1994). These representational systems are visual, auditory, and kinesthetic, where olfactory and gustatory are included. Individuals use all three representational systems to collect necessary data.

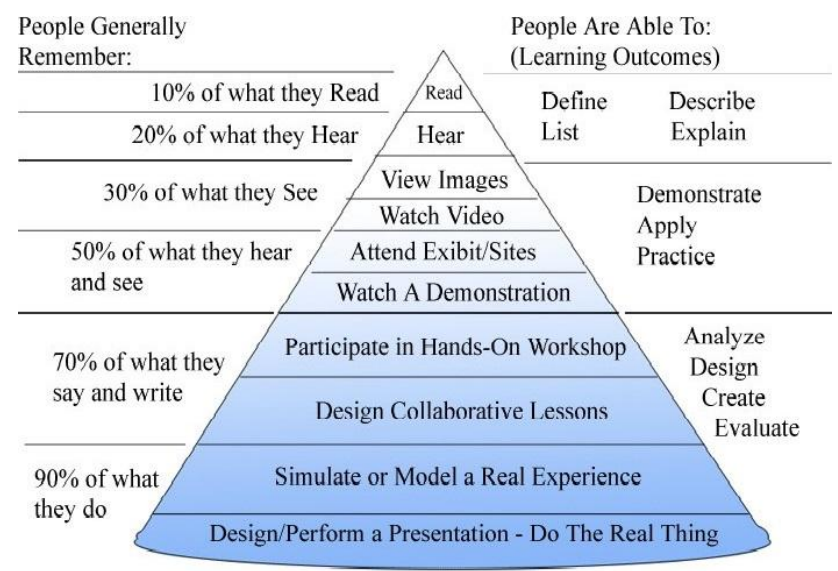

Fig1: Dale's Cone of Experience

However, each individual has a preference for one of these styles, and the learning process of these people can be enhanced by using preferred learning style. People with a visual preference accumulate more information about the 
world by constructing or using image like remembering methods. Auditory learners benefit learning through sounds and text and can better understand and interact with the world around them by listening or read. Those with a kinesthetic preference learn best through what they actually do. By implementing Visual, Auditory and Kinesthetic learning methods in his research, Dale has outlined that even though each has preferred learning styles, some are being more effective in the teaching-learning process than others placing them from top to bottom based on their effects on the learning process (Pashler, 2009).

Based on Dale's cone of experience, the least effective learning style is the Auditory learning style, involves data obtaining through verbal symbols such as listening to spoken words. On the other hand, he put the kineastetic learning style on the bottom of the con as the most effective learning style that involve direct, hands-on experiences in real or real- like environment (Fig1).

Information processing by the human brain is influenced by the learning environment, learning method implemented in the learning process. Based on Dale's findings "action-learning" techniques result in up to 90 percent recollection. People learn best when they use a Kinesthetic learning method. The kinesthetic learning method is multi-sensory based meaning there are more sensory channels activated during the resource interaction and there is a better chance for students to obtain more information (Diamond, 1989).

\section{Introduction to Augmented Reality and its current implementations}

The history of AR technology dates back to 1968 when Ivan Sutherland at the University of Utah, developed the first in it's kind head-mounted display system. The system used computer-generated graphics to show users simple wire-frame diagrams (Caudell, \& Mizell, 1992). Augmented Reality (AR) considers to be the variation of Virtual Reality (VR) technologies. With the use of VR technologies, a user gets completely immersed inside a synthetic environment. Being immersed in completely new reality, the user is unable to see the world around him (Azuma, 1997). In contrast, AR allows the user to see the real world, where computer-generated digital information (sound, video, graphics or GPS data) overlaid onto live direct or indirect physical real-world environment, thus enhancing user's perception of reality (Feng Zhou, Duh, \& Billinghurst, 2008; Grier, Thiruvengada, Havig, Hale, \& Hollands, 2012). Therefore, AR supplements reality, rather than completely replacing it. Ideally, it would appear to the user that the virtual and real objects coexisted in the same space. Augmented Reality enhances a user's perception of and interaction with the real world. The virtual objects display information that the user cannot directly detect with his senses. The information conveyed by the virtual objects helps a user perform real-world tasks. Being a cutting-edge technology there has been an increasing interest in applying Augmented Reality technology in many industries.

The flexibility and constant upgrade of open platforms available for developing AR applications with different content allow independent groups and organizations create field-specific applications and broadening the use of the AR technology (Mayilyan, Poghosyan, \& Avetisyan, 2018). 
As the name suggests the actual state of the reality augmented and the physical environment enhanced with supplemented information, AR has found a broad implementation in such industries where the transaction of a large amount of data to the user within a limited time is critical.

Having an excellent ability to establish a better relationship between consumer and brands AR technologies have found a wide implementation in advertising and marketing where companies are attempting new ways to engage and interest potential customers bringing a better brand awareness associated with potential sales (Baratali, Rahim, Parhizkar, \& Gebril 2016).

Blending AR into existing medical and healthcare systems enhances medicalsurgical and clinical procedures by reducing the complications of tissues, organs and major bones location delivery to surgeons improving cost-effectiveness, safety, and efficiency of current medical systems (Rashed, \& El-Seoud, 2017).

Being utilized in security and military domain AR technology helps pilot' s by overlaying collected and already analyzed target information into pilot' s headsup display ' s visual field, to enhance pilot's visibility range (Livingston, 2011).

AR applications help online shoppers with a broader introduction of the product's colors, size, etc. The advantage is that AR offers $3 \mathrm{D}$ realistic animation of the product, which assists the user with a better understanding of the product and how it can be used (Stoyanova, Goncalves, Coelhc, \& Brito, 2013).

Games powered with AR features create a unique environment where users can interact with the game characters in the actual environment, enhancing the real world and by having control over the characters in the real environment, bringing games from virtual environment to a real-life environment (Ranade, Zhang, Al-Sada, Urbani, \& Nakajima, 2017).

\section{AR in Education}

Integration of emerging technologies and advanced techniques such as Augmented Reality into formal education programs is becoming part of a good and productive teaching. Based on U.S. Department of Education assimilation of cutting-edge technologies such as Augmented Reality into the educational curriculum can bring the learning process out of classroom walls, broadening technology-student interaction from screen viewing and mouse clicking to entirely new learning environment, enriching the way students engage in the learning process (U.S. Department of Education, 2017)

The favorable benefits offered by Augmented Reality technologies in learning environment are massively infinite. There interactive nature of the The interactive nature and the favorable benefits offered by Augmented Reality technologies are massively infinite. There are several approaches and classifications such as discovery-based learning, objects modeling, skills training etc. enabling successfully integrate AR technologies into educational settings easily drives student's attention to the introduced subject resulting potential outcomes (Lee, 2012; Yuen, Yaoyuneyong, \& Johnson, 2011).

Augmented Reality technology has fund potential implementation in such disciplines where the spatial skills are important to acquire knowledge such as Biology, Chemistry and Anatomy, Geometry and Physics (Mayilyan, Poghosyan, \& Avetisyan, 2018). 


\section{AR Globe Project}

\section{A. Problem Statement}

To have a better understanding how AR technology performs in educational settings, its practical use in Natural Science studies, and the future integration in teaching-learning process, AR Globe project is proposed, which consists of physical globe and application. This pilot project was developed by YoungZone Culture (Shanghai) Co Ltd, a team of specialist from various countries including China, Armenia, Germany, Costa Rica, and Ukraine, to assess the potential of the AR Globe project as an AR educational tool. The design and engineering work of the project was completed by the end of 2017, and there were no proper implementation and assessment of the project in actual teaching-learning environment.

\section{B. Project Description}

The physical globe has design features that set it apart from the commonly accepted feature of globes. The colors of the globe, specially selected landmarks, and uniquely designed features of the globe attract immediate attention from learner's side. The physical parameters of the globe are set as Table 1:

Table 1: AR Glob's Physical Parameters

\begin{tabular}{|l|l|}
\hline Glob's Dimensions \\
\hline Net weight & $985 \mathrm{~g}$. \\
\hline Height & $28 \mathrm{CM}$ \\
\hline Ball diameter & $20 \mathrm{CM}$ \\
\hline
\end{tabular}

As mentioned above, for this project AR Globe application was developed, which is a subcategory of the NeoAR more massive project. The app is compatible with all devices for both iOS and Android operating systems.

Table 2: System Compatibility

\begin{tabular}{|l|l|l|}
\hline \multicolumn{3}{|l|}{ Compatibility with iOS and Android Operation Systems } \\
\hline & \multicolumn{1}{|l|}{} \\
\hline $\begin{array}{l}\text { Minimum } \\
\text { configuration }\end{array}$ & iOS 8.0+ OpenGLEs 2.0 & 4.0+ Open GL Es 2.0 \\
\cline { 2 - 3 } & 1G RAM 500M Storage & $\begin{array}{l}\text { 1G RAM 500M } \\
\text { Storage }\end{array}$ \\
\hline $\begin{array}{l}\text { Recommended } \\
\text { configuration }\end{array}$ & iOS 9.0+ OpenGLEs 2.0 & 5.0+ Open GLEs 2.0 \\
\cline { 2 - 3 } & 2 G RAM 1.5G Storage & 2 G RAM 1.5G Storage \\
\hline
\end{tabular}

For experiencing all the features of the AR Globe project, the user requires only a smart handheld device powered with a camera sensor, GPS sensor, accelerometer, compass as well as it should have a significant CPU, GPU, and RAM. Namely, the minimum requirements for each operating system are set as Table2:

Marker-based Augmented Reality was utilized for this project, where the texture of the globe considered to be the marker that is augmented. 
In marker-based $A R$, a marker refers to a fiducial marker. In AR applications, a fiducial marker can be any object that placed in front of the camera of the scanning device which has prior knowledge of the marker and can generate augmented information to visualize AR features assimilated with the marker.

The purpose of using the marker-based method of Augmented Reality technology for this project is to create a unique environment where learners are familiar with the use of the physical item and have a general concept of how the standard globes can benefit in their learning process. Another reason for using marker-based Augmented Reality technology for this project is to increase the level of interaction between students, physical and tangible object and the augmented information presented right on top of the item.

3D objects and animations of this project generated by Unity 3D Engine, where tracing and image recognition process powered by Vuforia an augmented reality software development kit (SDK).

Each learning element developed in this project has ways of information delivery to the users:

1. Auditory: Content introduced in form of text and a voice narrator developed to supplement information delivery.

2. Visual: object/content illustration with augmented 3D objects on top of the physical item.

3. Kinesthetically: provided 3D object are a subject of direct interaction by touching the virtual objects, rolling them in 360 degrees, moving up and down enlarge and reduce the object's size on the device screen, enhancing interaction-based learning.

\section{AR Globe Project Assessment}

Attitude is the emotions and feelings of a person generated through a particular experience of learning something new, something defined as target (Vonglao, 2017). Learning and personal experience can determine the person's attitude which is as same as the person's feelings, likes and dislikes, agreement or disagreement.

Due to it's latent and intangible nature, attitude considered as a subjective variable. Attitude exists, but it is not directly observable or measurable. Instead, attitude is measured by feelings, behaviors, expressions, and personal opinions, and the specific questionnaires are designed to obtain that data. Thus, choosing a correct measurement and data collection method for this variable is important.

Results of this experimental research were collected by using a qualitative research method through a questionnaire designed based on Likert scaling method (Likert 1932). Introduced by Rensis Likert in 1932, Likert scaling is the most widely accepted psychometric/attitude scale in survey research. Based on the Likert scaling, the respondents are asked to state the degree of their agreement with an assorting statement. In the original Linkert scale, labels were given to each feeling based on its agreement level: strongly disagree (SD), disagree (D), neither disagree nor agree (NN), agree (A) and strongly agree (SA). 
After the experiment, respondents/students were asked to assess their personal experience through a questionnaire designed to answer after a 45 minutes Geography class with implemented AR Globe.

The number of students participated in this project assessment was twenty-five. Learners were the 6th-grade students of the international school of Shanghai.

During the experiment, students were divided into five groups. Each group was assigned with a tablet with activated AR Globe application and one physical globe. As this was the first time students were interacting with an AR content in their learning process, they were briefly introduced with the main concept of the AR technology and the basic operations of the AR Globe application.

Selected study subjects for the particular class included three short lessons on the following topics:

1. Country introduction (P.R.C.) (Fig:2)

2. Structure of the Earth. (Fig:3)

3. Ocean Gyre. (Fig:4)
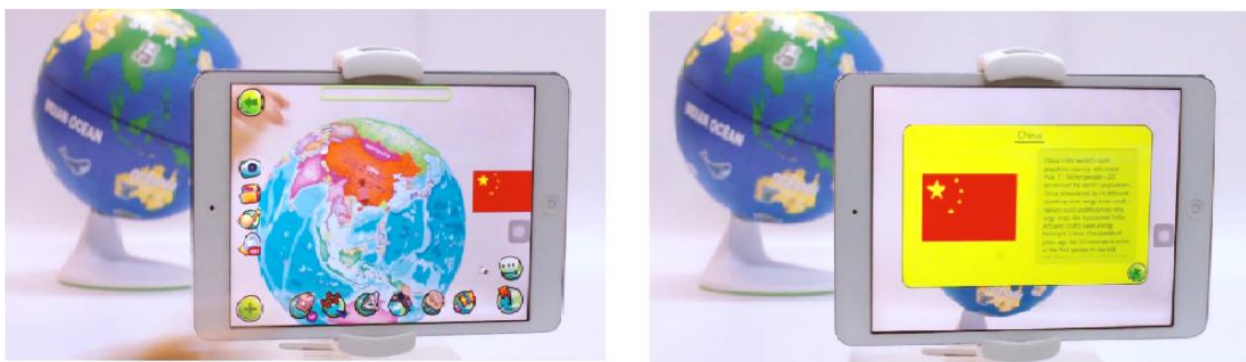

Fig2: Country Introduction
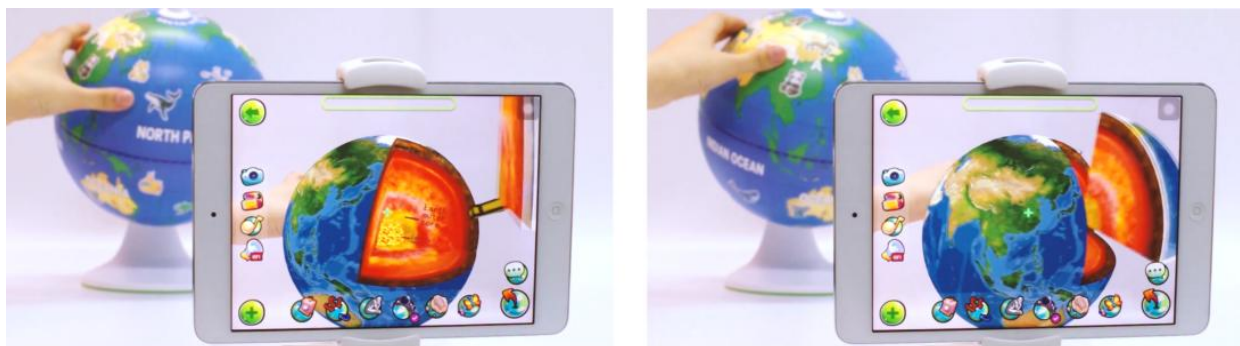

Fig3: Structure of the Earth
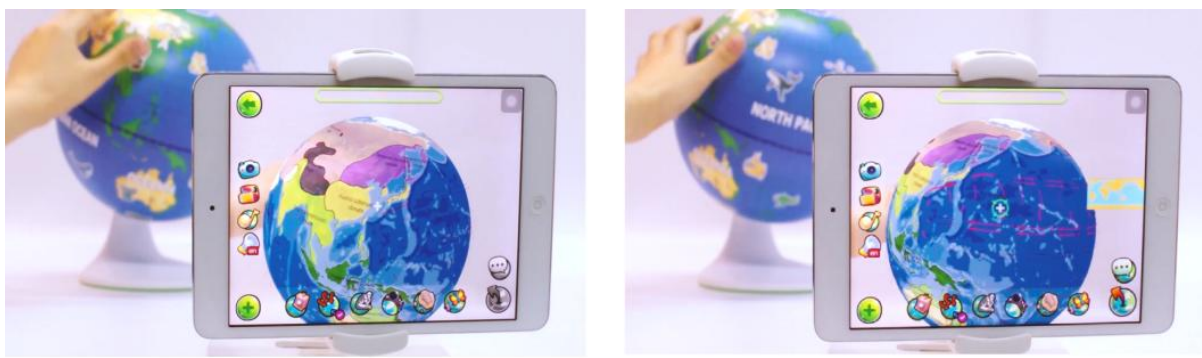

Fig4: Ocean Gyre 
Table 3 introduces the collection of the answers of the questionnaire collected from students after finishing the class. Part of the questions of the questionnaire was designed with questions that the answer on them will show how effective the AR Globe as an educational technology based on Edgar Dale's Cone of experience.

Table 3: Results Collected Through Qualitative Questionnaire

\begin{tabular}{|c|c|c|c|c|c|c|c|}
\hline & & & Stude & nts Res & onses & & \\
\hline & Q.1 & Q.2 & Q.3 & Q.4 & Q.5 & Q.6 & Q.7 \\
\hline 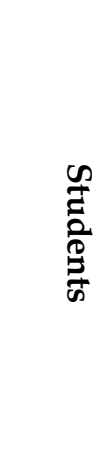 & 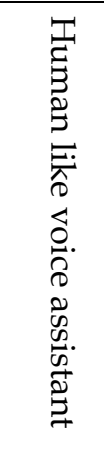 & 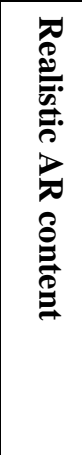 & 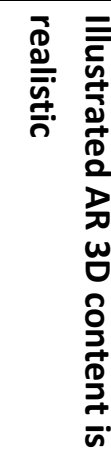 & 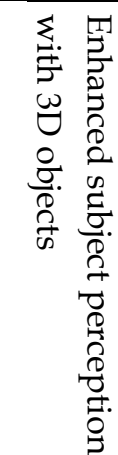 & 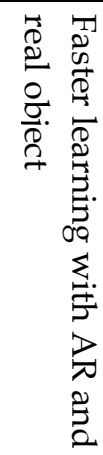 & 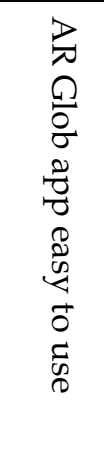 & 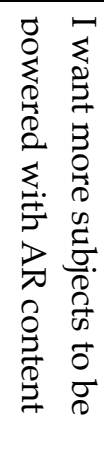 \\
\hline S1 & SA & SA & SA & SA & SA & A & SA \\
\hline S2 & A & SA & SA & SA & A & SA & SA \\
\hline S3 & SA & SA & SA & SA & SA & SA & SA \\
\hline S4 & SA & SA & SA & SA & A & A & SA \\
\hline S5 & SA & SA & $\mathrm{A}$ & A & SA & $\mathrm{A}$ & $\mathrm{A}$ \\
\hline S6 & SA & $\mathrm{A}$ & SA & SA & SA & SA & $\mathrm{A}$ \\
\hline S7 & SA & SA & SA & SA & SA & SA & SA \\
\hline S8 & SA & SA & A & SA & SA & A & SA \\
\hline S9 & A & SA & A & SA & SA & $\mathrm{N} / \mathrm{N}$ & A \\
\hline $\mathrm{S} 10$ & SA & SA & SA & SA & SA & SA & SA \\
\hline S11 & SA & SA & SA & SA & SA & SA & SA \\
\hline S12 & A & A & SA & SA & SA & A & A \\
\hline S13 & $\mathrm{N} / \mathrm{N}$ & A & A & SA & SA & A & SA \\
\hline S14 & SA & SA & SA & SA & SA & SA & SA \\
\hline S15 & SA & $\mathrm{A}$ & SA & SA & SA & SA & SA \\
\hline S16 & $\mathrm{A}$ & SA & SA & SA & SA & $\mathrm{A}$ & SA \\
\hline S17 & SA & SA & SA & SA & SA & SA & SA \\
\hline S18 & A & A & SA & SA & SA & A & A \\
\hline S19 & SA & SA & SA & SA & SA & A & SA \\
\hline S20 & SA & SA & SA & SA & SA & SA & SA \\
\hline S21 & SA & A & SA & SA & SA & $\mathrm{A}$ & SA \\
\hline S22 & $\mathrm{A}$ & SA & SA & SA & SA & SA & SA \\
\hline S23 & SA & SA & SA & SA & SA & SA & SA \\
\hline S24 & SA & A & SA & SA & SA & $\mathrm{A}$ & SA \\
\hline S25 & $\mathrm{A}$ & SA & SA & SA & SA & $\mathrm{A}$ & SA \\
\hline
\end{tabular}




$\begin{array}{ll}\text { Abbrv. } & \text { Meaning } \\ \text { SA } & \text { Strongly Agree } \\ \text { A } & \text { Agree } \\ \text { N/N } & \text { Neither Agree nor } \\ & \text { Disagree } \\ \text { DS } & \text { Disagree } \\ \text { SD } & \text { Strongly Disagree }\end{array}$

To understand which portion of learners of the assessment agree on implementing the AR Globe or any AR content in their learning environment collected results of the qualitative research are introduced with percentage values (1).

$$
V_{l . a .}=\frac{n_{l . a .}}{N} \cdot 100 \%
$$

$\begin{array}{ll}\text { Abbrv. } & \begin{array}{l}\text { Meaning } \\ \text { the level of collective } \\ V_{l a}\end{array} \\ n_{l a} & \begin{array}{l}\text { agreement } \\ \text { number of students with the } \\ \text { same level of agreement } \\ \text { total number of students. }\end{array} \\ N & \end{array}$

The results of this qualitative questionnaire with percentage presentation illustrated in table 4.

Table 4: Results of Qualitative Questionnaire Presented with Percentage Values

\begin{tabular}{|c|l|l|l|l|l|}
\hline \multicolumn{5}{|l|}{ Percentage of Agreement Level } \\
\hline Questions & SA & A & N/N & D & SD \\
\hline Q.1 & $68 \%$ & $28 \%$ & $4 \%$ & $0 \%$ & $0 \%$ \\
\hline Q.2 & $72 \%$ & $28 \%$ & $0 \%$ & $0 \%$ & $0 \%$ \\
\hline Q.3 & $84 \%$ & $16 \%$ & $0 \%$ & $0 \%$ & $0 \%$ \\
\hline Q.4 & $96 \%$ & $4 \%$ & $0 \%$ & $0 \%$ & $0 \%$ \\
\hline Q.5 & $92 \%$ & $8 \%$ & $0 \%$ & $0 \%$ & $0 \%$ \\
\hline Q.6 & $48 \%$ & $48 \%$ & $4 \%$ & $0 \%$ & $0 \%$ \\
\hline Q.7 & $80 \%$ & $20 \%$ & $0 \%$ & $0 \%$ & $0 \%$ \\
\hline
\end{tabular}

The table indicates several fundamental discoveries of students personal experience.

No students showed a negative feeling(s) towards the use of AR in their learning process with 0 percent of SD and D outcomes. Meaning of students feel comfortable using AR technology for acquiring information. It is notable that the highest level of agreement was given to the Q4 and Q5 respectively 96 percent and 92 percent.

These means that the implementation of AR technologies in formal education can increase the level of hands-on experience. Illustrating realistic 3D objects can create a unique ecosystem where students can experience more collaborative 
lessons. With advantages mentioned above, Augmented Reality educational technologies collect all the level of learning methods described by Edgar Dale's Cone of Experience, thus making AR a potential technology that can create significantly improved and engaged learning-teaching environment.

Besides the questionnaire, students added that the AR Globe presents the given information in combined, multidimensional manner such us text-audio, audio3D animation, 3D animation-direct interaction, significantly increase the pace of knowledge perception. Students repeatedly stated that within the given time they had learned more information than they would have during the usual class time.

\section{Conclusion}

In today's most available educational curriculum, student's learning process conducted with the use of paper-based learning materials. This learningteaching method limits the learning process especially subjects requiring advanced spatial skills (science, nature). One small misunderstanding of the topic may lead to a total uncertainty of a subject and even the whole discipline. These make the teaching-learning process a heavy duty for both students and teachers, enlarging the gap between student-instructor relationship creating a chaotic atmosphere in the learning environment.

Integration of cutting-edge technologies that simulates realistic hands-on experiences into educational programs, significantly improves the final results of teaching-learning process.

The aim of this project is to discover emerging Augmented Reality technology's benefits on the teaching-learning process. For correct evaluation marker-based AR Globe was proposed. Results gathered through specially designed questionnaire based on Likarts qualitative survey illustrate the attitude of learners.

The results showed important discoveries. Highest level of agreement was given to the questions associating AR Globe as a tool that increases the understanding of the subject through real like augmented object and the ability creating interaction between real object and the supplement data respectively 96 percent and 92 percent.

These shows implementation of emerging AR technology into educational domain significantly increases the results of teaching-learning process.

\section{References}

Ally, M. (2014). Increasing access through mobile learning. Vancouver, BC: Commonwealth of Learning.

Apter, M. J. (1967). The Development Of Audio- Visual Programmed Instruction. Programmed Learning and Educational Technology, 4(4), 302-315. doi:10.1080/1355800670040407

Auer, M. R. (2008). Sensory Perception, Rationalism and Outdoor Environmental Education. International Research in Geographical and Environmental Education, 17(1), 6-12. doi:10.2167/irgee225.0 
Azuma, R. (1997). A Survey of Augmented Reality. Presence: Teleoperators and Virtual Environments, 6 (4), pp. 355-385.

Baratali E., Rahim M.H.B Abd., Parhizkar B., Gebril Z.M.(2016). Effective Of Augmented Reality (AR) In Marketing Communication; A Case Study On Brand Interactive Advertising. International Journal of Management and Applied Science (IJMAS), 2(4), pp. 133-137.

Bandler, R., \& Grinder, J. (1980). Frogs into princes: Neuro-linguistic programming. Moab, UT: Real People Pr.

Burgelman, R. A., Maidique, M. A., and Wheelwright S. C. (2008) Strategic Management of Technology and Innovation: 5th Edd. Chicago, IL: McGraw-Hill Educatio.

Caudell, T., \& Mizell, D. (1992). Augmented reality: An application of heads-up display technology to manual manufacturing processes. Proceedings of the Twenty-Fifth Hawaii International Conference on System Sciences. doi:10.1109/hicss.1992.183317

Dale, E. (1969). Audio-visual methods in teaching. N.Y.: Holt.

Diamond, R. M. (1989). Designing and improving courses and curricula in higher education: A systematic approach. San Francisco: Jossey-Bass.

Dewey, J. (2015). Experience and education. New York: Free Press.

Education | Definition of education in English by Oxford Dictionaries. (n.d.). Retrieved from https://en.oxforddictionaries.com/definition/education

Fatt, J. P. (2000). Understanding the learning styles of students: Implications for educators. International Journal of Sociology and Social Policy, 20(11/12), 31-45. doi:10.1108/01443330010789269

Global Agenda Council on Ageing Technological Innovations ... (n.d.). Retrieved from http://www3.weforum.org/docs/WEF_Global_Population_Ageing_Technologi cal_Innovations_Health_Wealth_070916.pdf

Grant, M. M., \& Barbour, M. K. (n.d.). Mobile Teaching and Learning in the Classroom and Online. Handbook of Mobile Learning. doi:10.4324/9780203118764.ch25

Grier, R. A., Thiruvengada, H., Ellis, S. R., Havig, P., Hale, K. S., \& Hollands, J. G. (2012). Augmented Reality--Implications toward Virtual Reality, Human Perception and Performance. PsycEXTRA Dataset. doi:10.1037/e572172013-281

Hager, M. (1994). Target fluency: Leading edge foreign language teaching techniques. Portland, Oregón: Metamorphous Press.

Hsu, Y., Hung, J., \& Ching, Y. (2013). Trends of educational technology research: More than a decade of international research in six SSCI-indexed refereed journals. Educational Technology Research and Development, 61(4), 685-705. doi:10.1007/s11423-013-9290-9

Hughes, T. P. (2004). American genesis: A century of invention and technological enthusiasm, 1870-1970. Chicago: University of Chicago Press.

Hughes, T. P. (2005). Human-built world how to think about technology and culture. Chicago: University of Chicago Press.

Indonesia. (n.d.). Retrieved from http://www.ilo.org/dyn/natlex/natlex4.detail?p_lang=en\&p_isn=84435

Johnson, S. D. (1991). Productivity, the Workforce, and Technology Education. Journal of Technology Education, 2(2). doi:10.21061/jte.v2i2.a.4

Lee, K. (2012). Augmented Reality in Education and Training. TechTrends, 56(2), 13-21. doi:10.1007/s11528-012-0559-3

Lichtenberg, F. R. (2015). The impact of biomedical innovation on longevity and health. Nordic Journal of Health Economics, 5(1), 45. doi:10.5617/njhe.1290 
Likert R.(1932). A technique for measurement of attitudes. Archives of Psychology. Volume 140. pp 5-55.

Livingston M.A.(2011). Military Applications of Augmented Reality. In: Furht B. (eds) Handbook of Augmented Reality. New York, NY: Springer.

Mayilyan H., Poghosyan S., Avetisyan H.,(2018) Educational Augmented Reality Systems: Benefits of Implementation and Government Support, Proceedings of 4th International Conference of the Virtual and Augmented Reality in Education (VARE2018), 1.23-28

Pashler, H. (2009). Learning styles: Concepts and evidence. Hoboken, NJ: Wiley.

Ranade, S., Zhang, M., Al-Sada, M., Urbani, J., \& Nakajima, T. (2017). Clash tanks: An investigation of virtual and augmented reality gaming experience. 2017 Tenth International Conference on Mobile Computing and Ubiquitous Network (ICMU). doi:10.23919/icmu.2017.8330112

Rashed, E. A., \& El-Seoud, S. A. (2017). An interactive augmented reality imaging system for minimally invasive orthopedic surgery. 2017 2nd International Conference on Knowledge Engineering and Applications (ICKEA). doi:10.1109/ickea.2017.8169917

Reflections on the 2008 AECT Definitions of the Field. (2008). TechTrends, 52(1), 24-25. doi:10.1007/s11528-008-0108-2

Rhodes, R. (2001). Visions of technology: A century of vital debate about machines, systems and the human world. London: Simon \& Schuster.

Sandhu, M. S. (2016). A forum for global population health, technological advances and implementation science. Global Health, Epidemiology and Genomics, 1. doi:10.1017/gheg.2015.2

Stoyanova, J., Goncalves, R., Coelhc, A., \& Brito, P. (2013). Real-time augmented reality shopping platform for studying consumer cognitive experiences. 2013 2nd Experiment@ International Conference (exp.at13). doi:10.1109/expat.2013.6703069

Thomas, H. (2018). Powerful knowledge, technology and education in the future-focused good society. Technology in Society, 52, 54-59. doi:10.1016/j.techsoc.2017.09.005

S. DEPARTMENT OF EDUCATION. (2017). Reimagining the Role of Technology in Education: 2017 National Education Technology Plan Update 2. pp. 20-20, Washington, D.C. Retrived from.

Vonglao, P. (2017). Application of fuzzy logic to improve the Likert scale to measure latent variables. Kasetsart Journal of Social Sciences, 38(3), 337-344. doi:10.1016/j.kjss.2017.01.002

Yuen, S. C., Yaoyuneyong, G., \& Johnson, E. (2011). Augmented Reality: An Overview and Five Directions for AR in Education. Journal of Educational Technology Development and Exchange, 4(1). doi:10.18785/jetde.0401.10

Zhou, F., Duh, H. B., \& Billinghurst, M. (2008). Trends in augmented reality tracking, interaction and display: A review of ten years of ISMAR. 2008 7th IEEE/ACM International Symposium on Mixed and Augmented Reality doi:10.1109/ismar.2008.4637362 